\title{
FERTILIDADE E CARBONO DO SOLO E USO DA ÁGUA PELO EUCALIPTO NUMA TOPOSSEQUENCIA EM SEROPÉDICA, RJ ${ }^{1}$
}

\author{
Fabiano de Carvalho Balieiro ${ }^{2}$, Wellington Cruz Oliveira ${ }^{3}$, Marcos Gervasio Pereira ${ }^{3}$, Lúcia Helena Cunha \\ dos Anjos ${ }^{3}$, Marisa de Cássia Piccolo ${ }^{4}$ e Carlos Fellipe Jaccoud ${ }^{5}$
}

\begin{abstract}
RESUMO - A variabilidade espacial de atributos físicos, químicos, biológicos ou pedogenéticos é citada como responsável por padrões encontrados na distribuição do C e nutrientes do solo. Numa toposseqüência típica da Baixada Fluminense (Planossolo Háplico - PL, Argissolo Amarelo - AA e Argissolos Vermelho-Amarelos - AV1 e AV2), buscou-se avaliar a influência da paisagem na distribuição de atributos químicos e no uso da água e o crescimento do Eucalyptus urophylla. Amostras de solo foram coletadas ao acaso em três locais da toposseqüência, para caracterização da sua fertilidade, enquanto outras foram retiradas de trincheiras nas profundidades de 0-10, 10-20, 20-40, 40-60 e 60-100 cm, para avaliação do estoque de C. A circunferência à altura do peito (CAP) e a altura (ALT) e análise isotópica do $\delta^{13} \mathrm{C}$ de tecido foliar de plantas em cada terço da paisagem foram também avaliadas como parâmetros de crescimento e de eficiência do uso da água. Embora a fertilidade do solo tenha se relacionado com o material parental local, o crescimento do eucalipto parece estar mais relacionado com a dinâmica de água na paisagem que com a maioria dos atributos químicos do solo, pois os maiores valores de CAP e ALT foram encontrados nos terços médio e inferior da toposseqüência, menos férteis. Os valores de $\delta^{13} \mathrm{C}$ de amostras foliares de eucaliptos dos terços superior e inferior fortalecem essa hipótese. Os estoques de C dos solos $\left(4,75 \mathrm{~kg} \mathrm{~m}^{-2}\right.$ para o $\mathrm{PL}, 4,63 \mathrm{~kg} \mathrm{~m}^{-2}$ para o AA, 2,93 $\mathrm{kg} \mathrm{m}^{-2}$ para o AV2 e 2,60 $\mathrm{kg} \mathrm{m}^{-2}$ para o AV1) se relacionaram com as diferenças na densidade do solo, conseqüência da própria mineralogia. Dessa forma, conclui-se que o relevo tem forte influência sobre os atributos químicos do solo, embora haja evidências de o crescimento do eucalipto se relacionar com a disponibilidade de água no solo.
\end{abstract}

Palavras-chave: Matéria orgânica do solo, Eucalyptus urophylla e classes de drenagem.

\section{SOIL FERTILITY AND CARBON AND EUCALYPT WATER USE ON TOPOGRAPHY FEATURE IN SEROPÉDICA, RJ}

\begin{abstract}
Spatial variability of soil attributes (physical, chemical, biological or pedogenic) are related with some $C$ stock and nutrient distribution patterns. The influence of landscape on the distribution of chemical attributes, carbon stocks and the water use and Eucalyptus urophylla growth were evaluated on typical soil series and toposequence, on Seropédica, RJ. For soil fertility evaluation, samples were collected in a transect that divided the relief into three portions. For carbon stock estimation, samples at $0-10 ; 10-20 ; 20-40 ; 40-$ 60 and $60-100 \mathrm{~cm}$ depths were collected in each portion. Circumference at breast height (CAP) and height
\end{abstract}

\footnotetext{
${ }^{1}$ Recebido em 30.11.2006 e aceito para publicação em 18.12.2007.

${ }^{2}$ Embrapa Solos, Rua Jardim Botânico, 1024, Jardim Botânico, 22460-000 Rio de Janeiro-RJ. E-mail : <balieiro@cnps.embrapa.br>.

${ }^{3}$ Departamento de Solos da Universidade Federal Rural do Rio de Janeiro, Br 465, km 7, Campus Universitário da UFRRJ, 23890-000 Seropédica-RJ. E-mail :<gervasio@ufrrj.br>e <lanjos@ufrrj.br>.

${ }^{4}$ Centro de Energia Nuclear na Agricultura (CENA-USP). Av. Centenário, 303, Laboratório de Ciclagem de Nurtientes, 13416970 Piracicaba-SP. E-mail : <mpiccolo@cena.usp.br>.

${ }^{5}$ Agência de Florestas, Pesca e Biodiversidade do Instituto Estadual de Florestas (IEF).Três Marias-MG. E-mail : <cjaccoud@hotmail.com>.
} 
$(A L T)$ of plants and isotopic analysis of $\delta^{13} \mathrm{C}$ of foliar samples collected in distinct drainage class soils were used to evaluate the eucalypt growth and water use efficiency. Although soil fertility was related to changes in parental material, eucalyptus growth seems to be more related with water dynamics in the landscape since the highest CAP and ALT values were found in the lower, less fertile, slope positions. The $\delta^{13} C$ sign found in foliar tissues confirms this hypothesis. The C stocks on different soil class $\left(4.75 \mathrm{~kg} \mathrm{~m}^{-2}\right.$ for Fragiaquult, $4.63 \mathrm{~kg} \mathrm{~m}^{-2}$ for Typic Kannapludalf, $2.93 \mathrm{~kg} \mathrm{~m}^{-2}$ for Typic Kannapludalf_shoulder position and $2.60 \mathrm{~kg}$ $\mathrm{m}^{-2}$ for the Typic Kannapludalf_backslope) were related to mineralogy and particle organization (bulk density). It was concluded that relief could modify chemical attributes of soil and eucalyptus growth, especially through water availability.

Keywords: Soil organic matter, Eucalyptus urophylla and drainage class.

\section{INTRODUÇÃO}

O mecanismo de desenvolvimento limpo (MDL) proposto pelo Protocolo de Quioto (PQ) permite que países desenvolvidos e poluidores invistam em projetos que diminuam a emissão de gases de efeito-estufa e, ao mesmo tempo, promovam o desenvolvimento sustentável de países em desenvolvimento. Na primeira fase do PQ, com vigência até 2012, somente os projetos de afflorestation (aflorestamento) e reforestation (reflorestamento), no contexto de uso do solo, poderão ser aprovados (PEARSON et al., 2005). Desse fato, constata-se a implantação de projetos dessa natureza no território brasileiro a partir da década de 1990 (MAY et al., 2005).

Entre os seis compartimentos florestais passíveis de serem negociados no mercado de carbono (C), destacase a biomassa da parte aérea e da matéria orgânica do solo (MOS). A grande maioria dos projetos utiliza o primeiro compartimento devido, principalmente, à facilidade de mensuração e às rápidas mudanças nesse compartimento em períodos curtos de tempo (PEARSON et al., 2005). Entretanto, embora a mudança no estoque de carbono do solo necessite de períodos maiores para ser detectada, certamente esse reservatório representa um excelente compartimento para estocar o $C$ seqüestrado. A proteção física da fração mineral, as interações com os demais componentes do solo (biológico e químico) e o clima permitem que o solo se apresente como o maior compartimento de $C$ dos ecossistemas terrestres (FRANZLUEBBERS et al., 1996; WATSON, 2001; LAL, 2004).

A manutenção da MOS é requisito essencial para que o solo desempenhe suas funções. Embora o manejo e o clima exerçam forte influência sobre a dinâmica do $\mathrm{C}$ do solo, mudanças decorrentes da variabilidade espacial de atributos (físicos, químicos, biológicos do solo ou pedogenéticos) são citadas como responsáveis por determinados padrões (BERGSTROM et al., 1994; EPRON et al., 2004; MACHADO et al., 2004). O reconhecimento dessas mudanças, em nível local, pode auxiliar o entendimento dos processos que comandam a dinâmica de crescimento de essências florestais e do estoque de C do solo.

Diante do exposto, foi realizado um estudo sobre plantio de Eucalyptus urophylla S.T. Blake (eucalipto) com 3,5 anos de idade, com o objetivo de avaliar as mudanças na fertilidade e nos estoques de $\mathrm{C}$ do solo em uma toposseqüência e suas possíveis interações com variáveis de crescimento do eucalipto. Procurouse explicar também as variações no crescimento do eucalipto, por meio do seu consumo de água.

\section{MATERIAL E MÉTODOS}

\subsection{Descrição da área experimental}

A toposseqüência avaliada encontra-se em um plantio de eucalipto (Eucalyptus urophylla S. T. Blake) localizado na Universidade Federal Rural do Rio de Janeiro (UFRRJ), Município de Seropédica, a 22 ${ }^{\circ} 44^{\text {‘ }}$ $\mathrm{S} \mathrm{e} 43^{\circ} 42^{\circ} \mathrm{O}$ e altitude em torno de $26 \mathrm{~m}$. O clima, segundo Köopen, é do tipo Aw, com verões chuvosos e invernos secos. As médias mensais da temperatura mais baixa e mais alta são $20^{\circ}$ e $29^{\circ} \mathrm{C}$, respectivamente, com precipitação anual em torno de $1.250 \mathrm{~mm}$ (MATOS et al., 1998).

Entre os meses de dezembro de 2001 e janeiro de 2002, a empresa Saint Gobain canalização, com o objetivo de produzir matéria-prima para geração de carvão, realizou o plantio de eucalipto (a partir de mudas) no espaçamento 
5 x 2 m, em diversas áreas da UFRRJ. O manejo adotado durante a implantação e manutenção do plantio encontrase descrito por Corrêa Neto (2003). Contudo, anualmente a área foi queimada clandestinamente, o que obrigou a gradeação interna e externamente dos plantios, como forma de controle de gramíneas e manutenção de aceiros.

\subsection{Avaliação da fertilidade do solo}

Uma vertente com comprimento de rampa de 230 m e com declividade aproximada de $10 \%$ foi dividida em três terços (inferior-TI, médio-TM e superior-TS), de forma a estratificar a paisagem, coincidentemente com classes de solo distintas (Figura 1). De cada terço foram coletadas quatro amostras compostas, sendo estas confeccionadas a partir da mistura e homogeneização de sete amostras simples, retiradas com o auxílio de um enxadão. As amostras simples foram retiradas de pontos aleatórios de cada terço, de forma a representá-lo fielmente. Buscou-se retirar volumes iguais dessas amostras para a composição de cada composta. Cada amostra foi caracterizada quanto aos teores de Ca e Mg trocáveis, K e P disponíveis, C orgânico e pH (em água), acidez potencial $(\mathrm{H}+\mathrm{Al})$ e Al trocável. As análises foram realizadas no Laboratório de Fertilidade do Solo da UFRRJ seguindo-se metodologia proposta pela Embrapa (1997).

\subsection{Avaliação do estoque de $C$ do solo}

Quatro perfis foram estudados, encontrando-se distribuídos na vertente mencionada anteriormente, conforme a Figura 1, sendo o perfil 1 localizado no TI, classificado como Planossolo Háplico - PL; o perfil 2, no TM, classificado como Argissolo Amarelo (AA); e os perfis 3 e 4, no TS, como Argissolos VermelhoAmarelo (AV1 e AV2) (CORRÊA NETO, 2003).

A trincheira aberta possuía dimensões de $1,0 \mathrm{x}$ $1,0 \times 1,0 \mathrm{~m}$ e amostras em três das quatro faces das trincheiras foram coletadas nas profundidades de 010, 10-20, 20-40, 40-60 e 60-100 cm, com o auxílio de um anel de Kopeck, com $50 \mathrm{~cm}^{3}$ de volume.

O teor de $\mathrm{C}$ foi determinado segundo o método Walkley-Black, modificado(EMBRAPA, 1997). O estoque de carbono orgânico foi calculado pela seguinte equação:

$$
\mathrm{E}=(\mathrm{C} \times \mathrm{d} \times \mathrm{E}) / 100,
$$

em que, $\mathrm{E}=$ estoque de $\mathrm{C}$ do solo $\left(\mathrm{kg} \mathrm{m}^{-2}\right) ; \mathrm{C}=$ teor de $\mathrm{C}$ do solo $\left(\mathrm{g} \mathrm{kg}^{-1}\right)$; $\mathrm{d}=$ densidade do solo $\left(\mathrm{g} \mathrm{cm}^{-3}\right)$; e $\mathrm{E}=$ espessura da camada do solo $(\mathrm{cm})$.

Amostras de uma das faces de cada trincheira foram caracterizadas quanto à granulomentria, pelo método da proveta (EMBRAPA, 1997).

\subsection{Crescimento do eucalipto}

Por ocasião das amostragens, plantas de eucalipto, com 45 meses de plantio, foram avaliadas quanto à circunferência à altura do peito (CAP) e altura total (ALT), utilizando-se fita métrica e aparelho tipo Carl Leiss. De 88 a 102 e 20 a 30 plantas foram avaliadas quanto à CAP e à ALT, respectivamente, em cada terço. Visando auxiliar a discussão dos resultados, amostras de folhas da espécie, nos terços inferior e superior da toposseqüência, foram coletadas sete meses após as avaliações de solo e analisadas quanto à abundância natural do ${ }^{13} \mathrm{C}\left(\delta^{13} \mathrm{C} \%\right.$ ), com o auxílio do espectrômetro de massa Finnigan Delta Plus, no Laboratório de Ecologia Isotópica (CENA-USP), em Piracicaba. Os resultados foram expressos na forma de delta ${ }^{13} \mathrm{C}(\%)$ em relação ao padrão internacional PDB (Belemnitella Americana da formação Pee Dee). Essa análise possibilitou correlacionar a eficiência de uso de água, que está inversamente relacionada com a disponibilidade de água no solo, e o enriquecimento isotópico do tecido vegetal (OLBRICH et al., 1993).

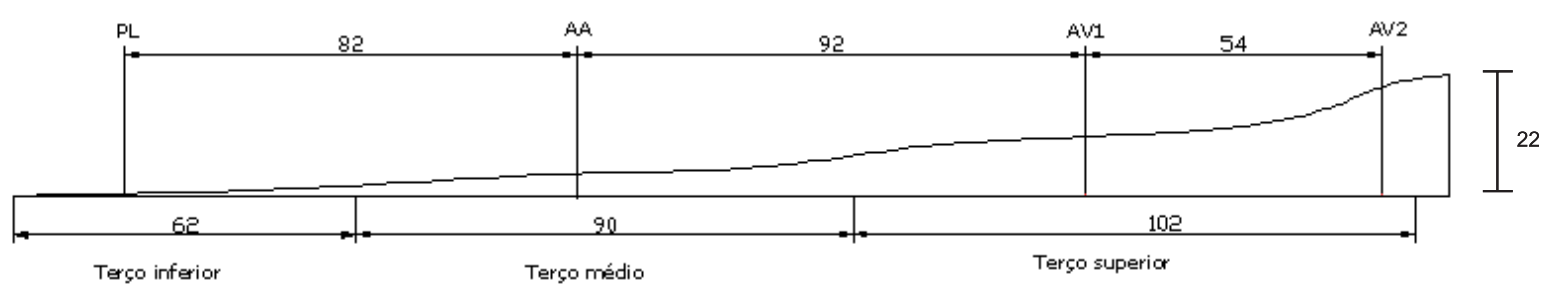

Figura 1 - Ilustração da toposseqüência estudada. PL: Planossolo Háplico; AA: Argissolo Amarelo; AV1: Argissolo VermelhoAmarelo 1; e AV2: Argissolo Vermelho-Amarelo 2. Os números apresentados representam as distâncias (em metros) entre as trincheiras e entre os terços.

Figure 1 -Toposequence illustration studied. PL: Fragiaquult; AA; Typic Kannapludalfbackslope; AV1: Typic Kannapludalf_shoulder position 1 and AV2: Typic Kannapludalf shoulder position 2). Numbers in the figure represent the meter scale. 


\subsection{Análise estatística}

Os atributos do solo de cada terço da vertente, bem como a CAP e ALT das plantas foram comparados pelo teste de Tukey em nível de $5 \%$ de probabilidade, depois de determinada a significância pela ANOVA, utilizando-se o Programa SAEG (EUCLYDES, 1983). Da mesma forma, compararam-se o teor de C das trincheiras abertas, nas diferentes profundidades, e os valores de $\delta^{13} \mathrm{C}$ de amostras foliares do eucalipto.

\section{RESULTADOS E DISCUSSÃO}

A fertilidade dos solos amostrados mostrou-se bastante diferenciada, evidenciando que o relevo possui forte influência sobre a distribuição dos nutrientes ao longo da toposseqüência (Tabela 1). Segundo Silva (1993), os cátions trocáveis dessa toposseqüência tendem a apresentar estreita relação com o material parental. Assim, o terço superior (principalmente) e o médio, formados a partir do intemperismo de rochas do PréCambriano subjacentes, apresentam-se mais ricos em bases que o inferior (PL), formado a partir da cobertura sedimentar pré-edafizada, com complexo sortivo mais pobre em bases (Tabela 1). Teores de Ca e Mg trocáveis foram significativamente superiores no terço superior, em comparação com o terço inferior da encosta. Os cátions $\mathrm{H}^{+} \mathrm{eAl}^{3+}$ foram os que predominaram no complexo sortivo dos solos, o que também foi verificado por Silva (1993) e Canellas et al. (2000), principalmente no perfil (PL) desenvolvido a partir de sedimentos. No Planossolo foram detectados (nas duas profundidades) o maior teor de P e o menor de K (à exceção da camada de $0-10 \mathrm{~cm}$ para o $\mathrm{K}$ ), e esse fato pode ser em decorrência do menor teor de argila desse solo, comparativamente aos demais da toposseqüência.

O crescimento do eucalipto não foi influenciado pelo aumento nas bases do solo, pois maiores valores de CAP e ALT foram encontrados nos terços médio e inferior (Figura 2), solos com menores teores de bases (Tabela 1). O teor de P nas camadas superficiais deve estar relacionado com os padrões de crescimento encontrados, mas possivelmente esse padrão esteja mais relacionado com a dinâmica da água na paisagem. Segundo Zaslavsky e Rogowski (1969), superfícies que apresentam contorno convexo no terço superior da paisagem provocam aumento no fluxo lateral e, ou, redução na taxa de infiltração da água, contrariamente a posição mais inferior da paisagem que permite maior taxa de infiltração e umidade do solo. Mesmo que a reserva de água disponível nas camadas superficiais dos Planossolos da região seja pequena (RAMOS et al., 1973; BALIEIRO et al., 2005), infere-se que a umidade em profundidade seja mantida pela presença do horizonte glei em subsuperfície e pela posição na paisagem, que mantêm o suprimento de água para as raízes das plantas por períodos mais longos. Stape et al. (2004), avaliando os principais fatores edafoclimáticos (incluindo a atributos químicos do solo), que controlam a produção e o uso dos recursos (água, nutrientes e luz) de 14 sítios de clones de Eucalyptus grandis e E. urophylla, verificaram que os atributos relacionados com a fertilidade do solo, a despeito do grande gradiente encontrado nos sítios, não se relacionaram com a produtividade dessa essência.

Tabela 1 - Valores médios de atributos químicos de amostras de solo de uma toposseqüência sob eucalipto, em Seropédica, RJ Table 1 - Average values for chemical attributes of some toposequence soil samples under eucalyptus, in Seropédica, RJ

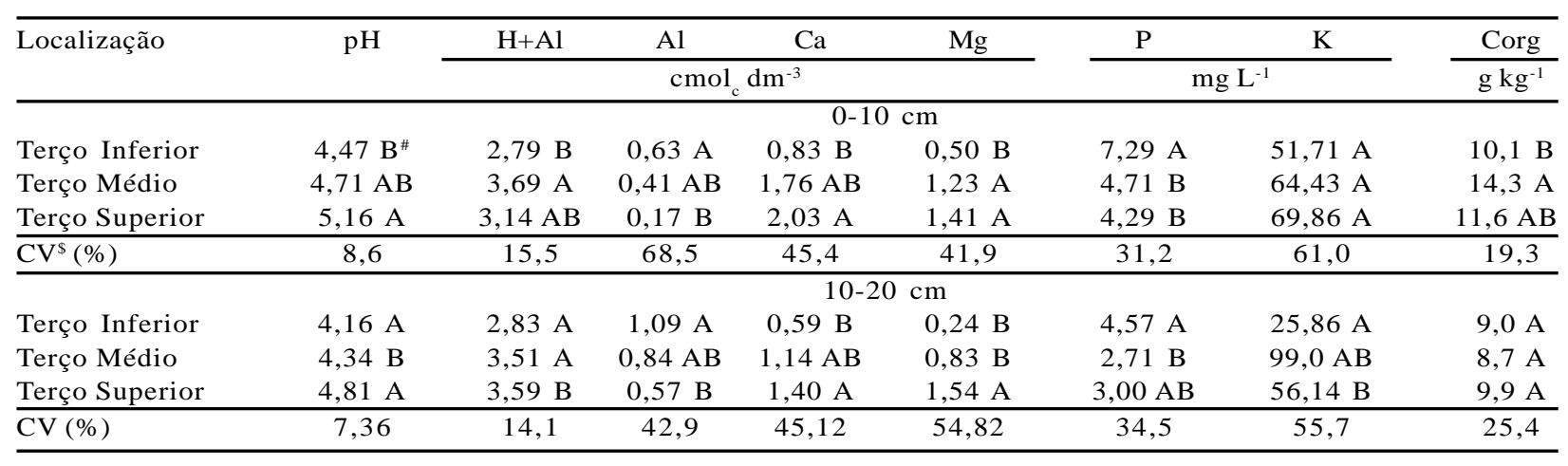

\# Letras diferentes numa mesma coluna (para cada profundidade) indicam diferença significativa entre as médias pelo teste de Tukey a 5\% de probabilidade; ${ }^{\$} \mathrm{CV}=$ coeficiente de variação. 


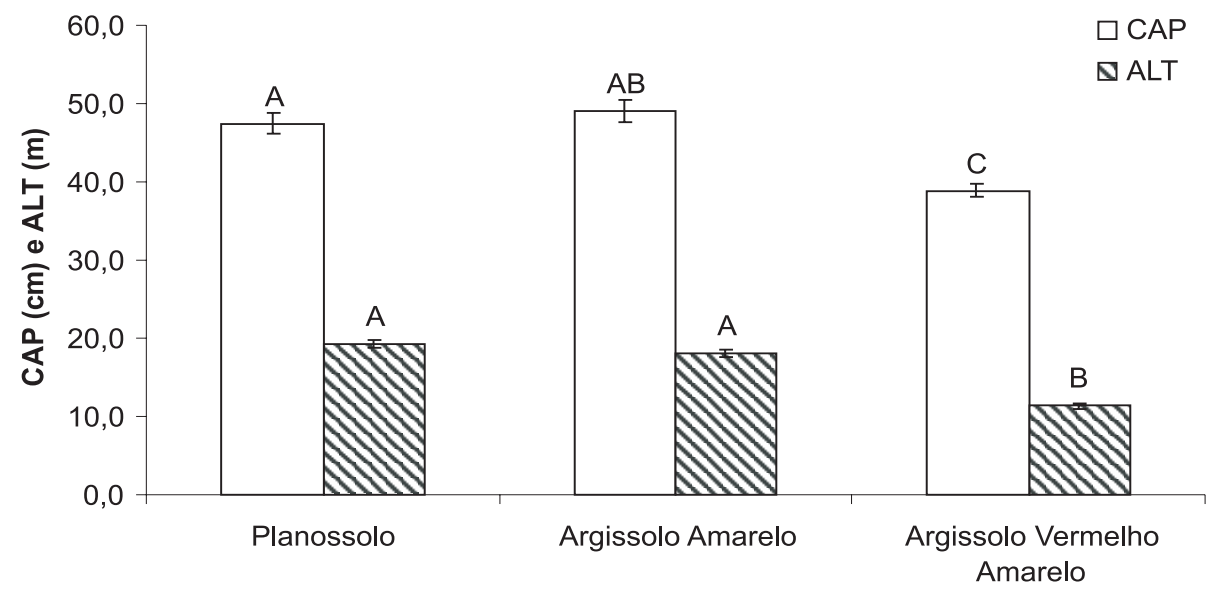

Classe de solo

Figura 2 - Altura (ALT) e circunferência à altura do peito (CAP) de plantas de eucalipto em diferentes classes de solo de uma toposseqüência em Seropédica, RJ. PL: Planossolo Háplico; AA: Argissolo Amarelo; e AV: Argissolo VermelhoAmarelo. Barras indicam erro-padrão, e barras com letras similares apontam que as médias não são diferentes pelo teste de Tukey $(\mathrm{p}<0,05)$.

Figure 2 - Eucalypt height (ALT) and circumference at breast height (CAP) under different soil classes in a toposequence in Seropédica, RJ. PL: Fragiaquult; AA; Typic Kannapludalfbackslope; AV: Typic Kannapludalf_shoulder position 1. Vertical bars indicate a standard error. Means indicated by bars, with the same letters are not significantly different by the Tukey test $(p<0.05)$.

A importância do suprimento de água ao eucalipto também é destacada por esses mesmos autores, ao avaliarem 14 sítios com gradiente de produtividade significativo (9,7-39,1 $\left.\mathrm{Mg} \mathrm{ha}^{-1} \mathrm{ano}^{-1}\right)$. Segundo aqueles autores, a produção líquida anual de biomassa (PLAB) dos sítios com nível médio de produtividade (média dos sítios $=16 \mathrm{Mg} \mathrm{ha}^{-1} \mathrm{ano}^{-1}$ ) foi $46 \%$ superior a PLAB dos sítios com nível baixo de produtividade (média de $11,9 \mathrm{Mg} \mathrm{ha}^{-1}$ ano $^{-1}$ ), sendo $32 \%$ dessa variação atribuída ao suprimento de água ao sítio. Embora a diferença de produtividade entre os sítios de alta e média produtividade tenha sido de $72 \%$, sendo um terço dessa diferença atribuída também à disponibilidade de água local. Na Bacia do Rio Doce, em Minas Gerais, Souza et al. (2006) detectaram que a produtividade do eucalipto, medida pelo incremento médio mensal de madeira, estava diretamente relacionada com a precipitação. Segundo esses autores, em cada acréscimo de $100 \mathrm{~mm}$ no total precipitado de um ano para o outro o aumento no incremento mensal foi, em média, de 0,445 $\mathrm{m}^{3}$ ha $^{-1}$ mês $^{-1}$, enquanto a redução de $100 \mathrm{~mm}$ diminuiu esse incremento em $0,64 \mathrm{~m}^{3}$ ha $^{-1}$ mês $^{-1}$. Rigatto et al. (2005) também encontraram correlações altíssimas entre a altura de plantas de Pinus taeda e a água disponível em oito diferentes sítios florestais.
Buscou-se comprovar essa hipótese com os resultados da análise isotópica de folhas da espécie. Foi observada maior discriminação do ${ }^{13} \mathrm{C}$ por plantas do terço inferior (PL), em comparação com as do terço superior (Figura 3), o que, segundo Olbrich et al. (1993) e Farquhar e Richards (1984), é um indicativo de que as plantas nesse local da paisagem usam, de forma menos eficiente, a água do solo, ou seja, passam mais tempo com seus estômatos abertos e, assim, são capazes de discriminar mais esse isótopo.

A distribuição do C orgânico nos perfis evidencia a importância do relevo na dinâmica do C do solo (Tabela 2). Os maiores teores de $C$ foram encontrados nos solos situados nos terços médio e superior devido, provavelmente, aos maiores porcentuais de argila nesses perfis (Figura 4), permitindo proteção adicional à decomposição da matéria orgânica do solo (MOS) (FRANZLUEBBERS etal., 1996; ROSCOE e MACHADO, 2002). No PL, a textura predominantemente arenosa favorece a oxidação da MOS devido a pouca proteção que essa fração exerce sobre essa. Somente na camada mais profunda $(60-100 \mathrm{~cm})$, o teor de $C$ nesse solo excede (significativamente) os valores encontrados nos demais perfis, devido à presença do horizonte de iluviação 
da argila de camadas superiores e a provável lixiviação de formas dissolvidas ou solúveis de C. Canellas et al. (2000), estudando a mesma toposseqüência sob vegetação predominante de gramíneas das espécies Melinis minutuflora, Panicum maximum e Imperata brasiliensis, detectaram teores mais elevados de C em todos os perfis, além de mudanças na distribuição das frações húmicas do solo. Os resultados indicaram que a prática de gradagem do solo, com o intuito de controlar plantas daninhas, e o próprio fogo têm sido responsáveis pela diminuição nos teores de C do solo. Nota-se também que a maior parte do C se encontra nos $40 \mathrm{~cm}$ superficiais, sendo essa evidência mais forte nos solos do terço superior, com maiores teores de argila superficialmente.

Os estoques de $\mathrm{C}$ dos solos $\left(4,75 \mathrm{~kg} \mathrm{~m}^{-2}\right.$ para $\mathrm{PL}$, $4,63 \mathrm{~kg} \mathrm{~m}^{-2}$ para AA, 2,93 $\mathrm{kg} \mathrm{m}^{-2}$ para o AV2 e 2,60 kg

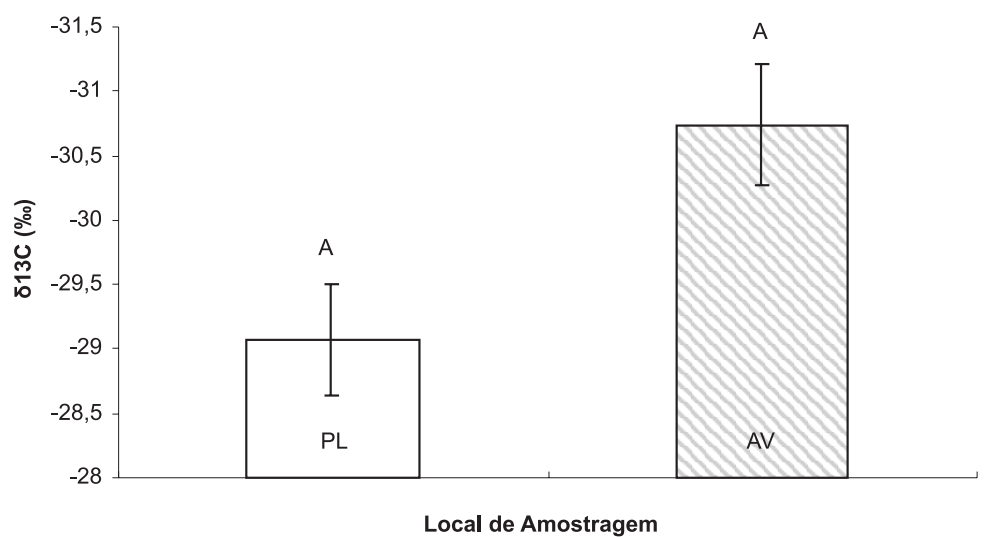

Figura 3 - Composição isotópica $\left(\delta^{13} \mathrm{C}\right.$, \%o) de folhas de eucalipto plantado em Planossolo e Argissolo Vermelho-Amarelo. Barras verticais indicam erro-padrão, e barras com letras similares apontam que as médias não são diferentes pelo teste de Tukey $(\mathrm{p}<0,05)$.

Figure 3 - Isotopic composition $\left(\delta^{13} C, \%\right.$ ) of eucalypt leaves planted on a Fragiaquult (PL) Typic Kannapludalf shoulder slope (AV). Vertical bars indicate a standard error. Means indicated by bars, with the same letters are not significantly different by the Tukey test $(p<0.05)$.

Tabela 2 - Teor de C em diferentes camadas de um Planossolo Háplico, de um Argissolo Amarelo e dois Argissolos VermelhoAmarelos, numa toposseqüência sob plantio de eucalipto

Table 2 - Carbon content in different layers of a Fragiaquult (PL), a Typic Kannapludalf backslope (AA), a Typic Kannapludalf _shoulder position 1 (AV1) and a Typic Kannapludalf shoulder position 2 (AV2)

\begin{tabular}{cccr}
\hline Profundidade $(\mathrm{cm})$ & PL & AA & AV1 \\
\cline { 2 - 4 } & & & $\mathrm{g} \mathrm{kg}^{-1}$ \\
\hline $0-10$ & $46,6 \mathrm{~B}$ & $56,0 \mathrm{~B}$ & $90,5 \mathrm{~A}$ \\
$10-20$ & $43,1 \mathrm{~B}$ & $75,4 \mathrm{AB}$ & $\mathrm{AB}$ \\
$20-40$ & $23,0 \mathrm{C}$ & $61,4 \mathrm{~A}$ & $30,3 \mathrm{BC}$ \\
$40-60$ & $23,6 \mathrm{~A}$ & $45,2 \mathrm{~A}$ & $22,4 \mathrm{~A}$ \\
$60-100$ & $38,9 \mathrm{~A}$ & $32,0 \mathrm{~A}$ & $35,3 \mathrm{~B}$ \\
\hline
\end{tabular}

\# Letras diferentes numa mesma linha indicam diferença significativa entre as médias pelo teste de Tukey a 5\% de probabilidade; ${ }^{\$} \mathrm{CV}=$ coeficiente de variação. ${ }^{\$} \mathrm{CV}$ : coeficiente de variação: 0-10 cm: 18\%; 10-20 cm: 11,6\%; 20-40 cm: 10,3\%, 40-60 cm: $15,4 \%$

e $60-100 \mathrm{~cm}: 13,6 \%$.

R. Árvore, Viçosa-MG, v.32, n.1, p.153-162, 2008 $\mathrm{m}^{-2}$ para AV1) parecem se relacionar com as diferenças minerais formadores da fase sólida dos solos, pois acentuadas quanto à densidade (Tabela 2 e Figura ). No PL; o quartzo é o mineral predominante, ao enriquecimento ao longo da toposseqüência de minerais facilmente intemperizados como a mica e menor que a do quartzo. Caso o estoque de $C$ fosse corrigido para a massa de solo das trincheiras, seqüência: AV1 (2,32 $\left.\mathrm{kg} \mathrm{m}^{-2}\right)$, PL (2,70 $\left.\mathrm{kg} \mathrm{m}^{-2}\right)$, AV2 $\left(2,93 \mathrm{~kg} \mathrm{~m}^{-2}\right)$ e AA $\left(3,47 \mathrm{~kg} \mathrm{~m}^{-2}\right)$. 

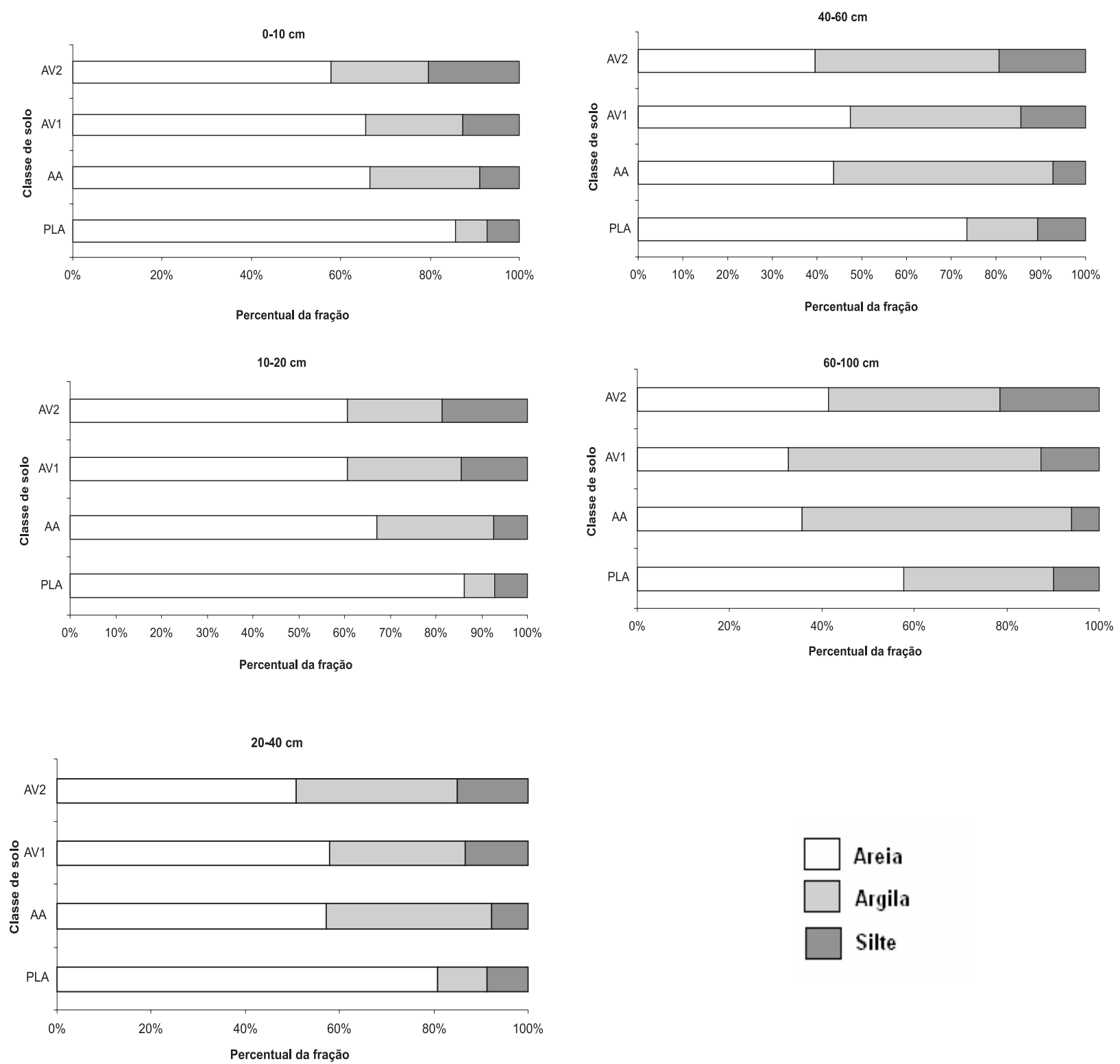

Figura 4 - Distribuição porcentual das frações granulométricas de amostras retiradas de diferentes classes de solo sob um plantio de Eucalyptus urophylla. PLA: Planossolo Háplico; AA: Argissolo Amarelo; AV1: Argissolo VermelhoAmarelo 1 e AV2: Argissolo Vermelho-Amarelo 2.

Figure 4-Distribution of the granulometric particles in different soil classes and under a Eucalyptus urophylla plantation. PL: Fragiaquult; AA; Typic Kannapludalf backslope; AV1: Typic Kannapludalf_shoulder position 1 and AV2: Typic Kannapludalf shoulder position 2.

Numa toposseqüência englobando Neossolo Quartzarênico e um Latossolo Vermelho sob plantio de Eucalyptus camaldulensis Dehnh e áreas nativas de Cerrado, Zinn et al. (2002) detectaram que as maiores perdas de carbono $(0-60 \mathrm{~cm})$ se deram sob o solo arenoso,
$9 \mathrm{Mg} \mathrm{ha}^{-1}$ ou $17 \%$, comparativamente à área-controle (Cerrado). Na camada superficial $(0-5 \mathrm{~cm})$, a perda foi altamente dependente da textura do solo, sendo equivalente a 23 e $48 \%$ nos solos argiloso e arenoso, respectivamente. Os estoques de $\mathrm{C}$ encontrados nos primeiros $40 \mathrm{~cm}$ de 
solo, por Zinn et al. (2002), em Neossolo Quartzarênico, são ligeiramente maiores $\left(3,0 \mathrm{~kg} \mathrm{~m}^{-2}\right.$ sob o eucalipto e $4,1 \mathrm{~kg} \mathrm{~m}^{-2}$ sob o Cerrado) que os reportados neste trabalho, certamente devido às diferenças no porcentual de argila das áreas (>13\% no Neossolo Quartzarênico e <4\% no
Planossolo) e idade dos plantios (5 anos vs. 7 anos). Esses resultados evidenciam que solos arenosos dependem de um manejo mais conservacionista, pois, além de não possuírem capacidade de estocar grande quantidade de C, podem perdê-lo muito rapidamente.

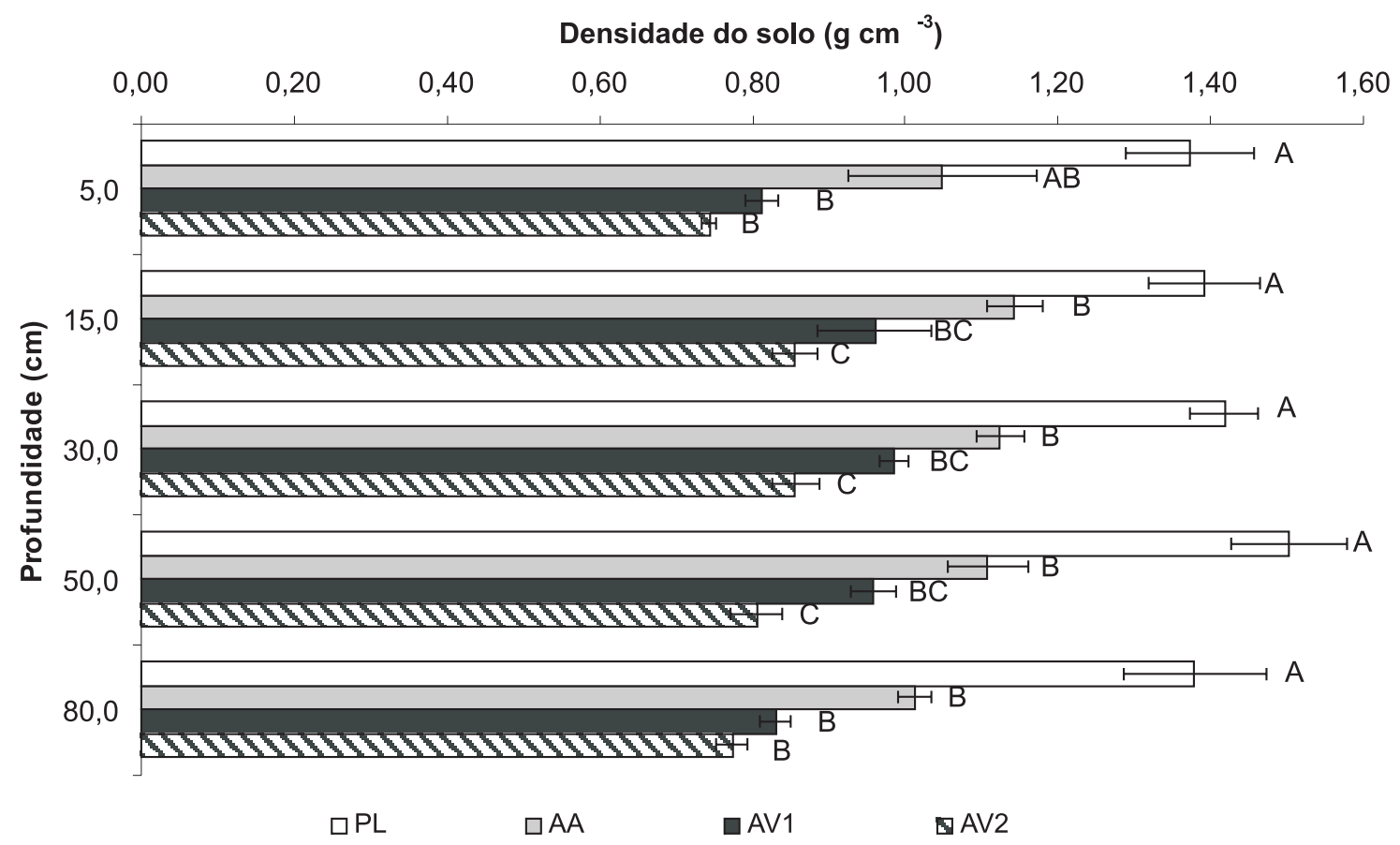

Figura 5 - Densidade de solos amostrados em diferentes locais de uma toposseqüência de Seropédica, RJ. PL: Planossolo Háplico; AA: Argissolo Amarelo; AV1: Argissolo Vermelho-Amarelo 1; e AV2: Argissolo Vermelho-Amarelo 2. Barras em cada profundidade e solo indicam erro-padrão da média, e barras com letras similares, numa mesma profundidade, apontam que as médias não são diferentes pelo teste de Tukey $(\mathrm{p}<0,05)$.

Figure 5 - Bulk densities of soils sampled in different positions of a toposequence in Seropédica, RJ. PL: Fragiaquult; AA; Typic Kannapludalf backslope; AV1: Typic Kannapludalf_shoulder position 1 and AV2: Typic Kannapludalf shoulder position 2. Horizontal bars indicate standard error. Means indicated by bars, with the same letters and for the same soil layer are not significantly different by the Tukey test $(p<0.05)$.

Tabela 3 - Estoque de C em diferentes camadas de um Planossolo Háplico de um Argissolo Amarelo e dois Argissolos VermelhoAmarelos, numa toposseqüência sob plantio de eucalipto. Valores entre parênteses indicam o porcentual estocado em cada camada

Table 3 - Carbon stocks in different layers of a Fragiaquult (PL), a Typic Kannapludalf backslope (AA), a Typic Kannapludalf _shoulder position 1 (AV1) and a Typic Kannapludalf shoulder position 2 (AV2)

\begin{tabular}{ccccc}
\hline Profundidade $(\mathrm{cm})$ & PL & AA & AV1 & AV2 \\
\cline { 3 - 5 } & & $0,79(17,1)$ & $0,46(17,5)$ & $0,67(23,0)$ \\
\hline $0-10$ & $0,64(13,5)$ & $0,70(15,2)$ & $0,46(17,8)$ & $0,45(15,5)$ \\
$10-20$ & $0,60(12,6)$ & $1,02(22,0)$ & $0,60(23,0)$ & $0,61(20,7)$ \\
$20-40$ & $0,65(13,7)$ & $0,71(15,3)$ & $0,43(16,6)$ & $0,49(16,6)$ \\
$40-60$ & $0,71(14,9)$ & $1,41(30,5)$ & $0,65(25,1)$ & $0,71(24,1)$ \\
$60-100$ & $2,15(45,2)$ & 4,63 & 2,60 & 2,92 \\
\hline Total & 4,75 & & &
\end{tabular}

R. Árvore, Viçosa-MG, v.32, n.1, p.153-162, 2008 


\section{CONCLUSÃO}

Der acordo com os resultados, chegou-se às seguintes conclusões.

- O relevo tem forte influência sobre os atributos químicos do solo, embora haja forte evidência de o crescimento do eucalipto se relacionar com a disponibilidade de água na paisagem e com o teor de P no solo.

- Os estoques de C do solo, na toposseqüência e nas diferentes profundidades, relacionam-se com a posição na paisagem e com o teor de argila de cada local de amostragem, indicando que o manejo adotado na área tem conseqüências diferenciadas sobre esse atributo.

\section{AGRADECIMENTOS}

À CAPES, pela bolsa e pelos recursos disponibilizados pelo Programa PRODOC ao primeiro autor.

\section{REFERÊNCIAS}

BALIEIRO, F. C. et al. Biomassa radicular e regime hídrico do solo em plantio de guachapele num Planossolo Háplico. Revista Floresta, v.35, n.2, p.221-230, 2005.

BERGSTROM, D. W.; MONREAL, C. M.; JACQUES, E. S. Spacial dependence of soil carbon mass and its relationship to soil series and topography. Canadian Journal Soil Science, v.81, n.1, p.53-62, 1994.

CANELLAS, L. P. et al. Frações da matéria orgânica em seis solos de uma topossequencia no Estado do Rio de Janeiro. Pesquisa Agropecuária Brasileria, v.31, n.1, p.133-143, 2000.

CORRÊA neto, T. A. Aporte de material decíduo e fauna do solo em áreas de floresta secundária e de plantio de eucalipto na FLONA Mário Xavier, Seropédica, RJ. 2002. 36f. Dissertação (Mestrado em Ciência do Solo) - Universidade Federal Rural do Rio de Janeiro, Seropédica, 2003.

EMPRESA BRASILEIRA DE PESQUISA AGROPECUÁRIA - EMBRAPA. Manual de métodos de análise de solo. Rio de Janeiro: 1997. 212p.
EPRON, D. et al. Spatial and temporal variations of soil respiration in a Eucalyptus plantation in Congo. Forest Ecology and

Management., v.202, n.1/3p.149-160, 2004.

EUCLYDES, R. F. Manual de utilização do programa SAEG (Sistema para análises estatísticas e genéticas). Viçosa, MG: Imprensa Universitária, 1983. 59p.

FARQUHAR, G. D.; RICHARDS, R. A. Isotopic composition of plant carbon correlates with water use efficiency of wheat genotypes.

Australian Journal of Plant

Physiology, v.11:539-552, 1984.

FRANZLUEBBERS, A. J. et al. Active fractions of organic matter in soils with different texture. Soil Biology and Biochemistry, v.28, n.10/11, p.1367-1372, 1996.

LAL, R. Agriculture activities and the global carbon cycle. Nutrient Cycling in Agroecossytems, v.70, n.2, p.103-116, 2004.

MACHADO, P. L. O. A. et al. Especialização do estoque de carbono do solo em lavoura de soja. In: MACHADO, P. L. O. A.; BERNARDI, A. C. C.; SILVA, C. A. (Eds.) Agricultura de precisão para o manejo da fertilidade do solo em sistemas de plantio direto. Rio de Janeiro: Embrapa Solos, 2004. p.165-174.

MATOS, C. C. L. et al. Boletim agrometeorológico. Revista Floresta e Ambiente, v.5, n.1, p.208-215, 1998.

MAY, P. et al. Incorporando o desenvolvimento sustentável nos projetos de carbono florestal no Brasil e na Bolívia. Estudos Sociedade e Agricultura, v.13, n.1, p.5-50, 2005.

NEILL, C. et al. Soil carbon and nitrogen stocks following forest clearing for pasture in the southwestern Brazilian Amazon. Ecological Applications, v.7, n.4, p.1216-1225, 1997.

OLBRICH, B. W. et al. Variation in water use efficiency and $\delta^{13} \mathrm{C}$ levels in Eucalyptus grandis clones. Journal of Hidrology, v.150, n.2/4, p.615-633, 1993.

R. Árvore, Viçosa-MG, v.32, n.1, p.153-162, 2008 
PEARSON, T.; WALKER, S.; BROWN, S.

Sourcebook for land use, land-use

change and forestry projects.

BioCarbonFund, 2005, 57p. (www.carbonfinance.org)

RAMOS, D. P.; CASTRO, A. F.; CAMARGO, M. N. Levantamento detalhado de solos da área da Universidade Federal Rural do Rio de Janeiro. Pesquisa Agropecuária Brasileira, v.8, p.1-27, 1973.

RIGATTO, P. A.; DEDECEK, R. A.; MATTOS, J. L. $M$. Influência dos atributos do solo sobre a produtividade do Pinus taeda. Revista Árvore, v.29, n.5, p.701-709, 2005.

ROSCOE, R.; MACHADO, P. L. O

Fracionamento físico do solo em estudos da matéria orgânica. Dourados: Embrapa Agropecuária Oeste; Rio de Janeiro: Embrapa Solos, 2002. 86p.

SILVA, M. B. Caracterização dos solos em uma toposseqüência no Campus da UFRRJ. 1993. 141f. Dissertação (Mestrado em Ciência do Solo) - Universidade Federal Rural do Rio de Janeiro, Seropédica, 1993.

SOUZA, M. J. H. et al. Disponibilidade hídrica do solo e produtividade do eucalipto em três regiões da Bacia do Rio Doce. Revista Árvore, v.30, n.3, p.399-410, 2006.
STAPE, J. L.; BINKLEY, D.; RYAN, M. G.

Eucalyptus production and the supply, use and efficiency of the use of water, light and nitrogen across a geographic gradient in Brazil. Forest Ecology and Management, v.193, n.1/3, p.17-31, 2004.

WATSON, R. T. (Ed.) Climate Change 2001: Synthesis report third assessment report of the Intergovernmental Panel on Climate Change (IPCC). Cambridge: University Press, 2001. 397p.

VELDKAMP, V. A. C. et al. Organic carbon turnover in three tropical soils under pasture after deforestation. Soil Science Society America Journal, v.58, n.1, p.175-180, 1994.

ZASLAVSKY, D.; ROGOWSKY, A. S. Hydraulic and morphologic implications of anisotropy and infiltration in soil profile development. Soil Science Society America Proceedings, v.33, p.594-599, 1969.

ZINN, Y. L.; RESCK, D. V. S.; SILVA, J. E. Soil organic carbon as affected by afforestation with Eucalyptus and Pinus in the Cerrado region of Brazil. Forest Ecology and Management, v.166, n.1/3, p.285-294, 2002. 